\title{
Research on Constructing Innovation and Enterprise Education Quality Evaluation System of Application Oriented University
}

\author{
Kefei Wang ${ }^{1, a^{*}}$, Ming Lu ${ }^{1, b}$ and Hongdi Ke ${ }^{1, \mathrm{c}}$ \\ 1 Department of Technology,Jilin Business and Technology College,Changchun 130507,China \\ a wangkefei888@sina.com, b975579008@qq.com, c13661033@qq.com
}

\begin{abstract}
Keywords: Application Oriented University; Innovation and Enterprise Education; Combination Evaluation;Quality Evaluation System
\end{abstract}

\begin{abstract}
This paper proposes a new innovation and entrepreneurship education evaluation system, the system is based on the principle of objective evaluation and objective evaluation,subjective evaluation by improved AHP, objective evaluation by combination evaluation method, And through the inspection in advance and afterwards analysis to evaluate the effectiveness of the method's validation. On the principle of highlights the objective evaluation , Puts forward a kind of optimization algorithms which combines both subjective evaluation and objective evaluation to solve the shortage of the single analysis method, Then makes analysis conclusion more objective and more scientific.
\end{abstract}

\section{Introduction}

Innovation and enterprise education is a new needs of colleges and universities in recent years, its quality evaluation is based on values of education or education goals. Because of the process of innovation and entrepreneurship education is multi-level, many series[1,2], many factors such as characteristics, according to training goal,set up the education quality evaluation system which cultivates the innovative entrepreneurial quality and ability as the center,and can supervise the process of education and performance comprehensively[3]. one hand, effectively avoid the waste of the university innovation entrepreneurship education resources, improve the innovative entrepreneurial education function of the cross is applied, on the other hand, make students form the reasonable expectations of entrepreneurship education, and promote the exchange and study of the creative education abroad advanced level.

\section{The Overview of Innovation and Enterprise Education Quality Evaluation Both at Home and Abroad}

There are hundreds of different comprehensive evaluation methods at home and abroad, Due to different methods, the mechanism of various methods of attribute level, there are different evaluation conclusions between the application of each method. In order to solve this problem, the academia puts forward the train of thought for studying the " combination evaluation ",and achieved certain results. for example, Guo Xianguang put forward the method using the "average", "the Borda method", "Copeland method" and "fuzzy Borda method" and other four methods and conclusions of different evaluation methods are combined[4,9].Zeng Xianbao proposed separately in KENDALL coefficient of consistency test and SPEARMAN rank correlation coefficient test for before-and-after testing combination evaluation.Zeshui Xu, Lin Yuanqing and Dingxiang Mao from the multiple attribute of the combination evaluation object empowerment to discuss the combined method of empowerment[5.6], and using the mathematical programming method and the least square method to solve.

Obviously, above research results to solve the comprehensive evaluation method for evaluation conclusion in the process of inconsistency problem provides a good idea. 


\section{Comprehensive Evaluation Index System Setting}

From the level of applied undergraduate college innovation entrepreneurship education of many factors, Combining with the characteristics of innovative entrepreneurship research activities[7,8], Investigating a large amount of data, text data, and some experts point of view, then based on the theory of index system analysis, compare the different types of evaluation index system of creative education in university, Applied undergraduate university creative education evaluation index system structure as shown in table 2.1

Table1: innovation and entrepreneurship education evaluation system of application oriented university

\begin{tabular}{|c|c|c|}
\hline \multirow{17}{*}{$\begin{array}{l}\text { innovation and } \\
\text { entrepreneurship } \\
\text { education evaluation } \\
\text { system of application } \\
\text { oriented university }\end{array}$} & $\begin{array}{c}\text { Level } 2 \\
\text { indicators }\end{array}$ & Level 3 indicators \\
\hline & \multirow{3}{*}{ course } & Core curriculum evaluation \\
\hline & & Relevant material relevant to degrees \\
\hline & & The teaching method reform \\
\hline & \multirow{5}{*}{ teacher } & Management mode \\
\hline & & Double teacher ability \\
\hline & & Scientific research level \\
\hline & & Enterprise experience or experience \\
\hline & & Performance appraisal mechanism \\
\hline & \multirow{3}{*}{ student } & Entrepreneurial background \\
\hline & & The ability to practice \\
\hline & & $\begin{array}{l}\text { Innovative entrepreneurial experience and } \\
\text { willingness }\end{array}$ \\
\hline & \multirow{3}{*}{ method } & $\begin{array}{l}\text { Innovative entrepreneurial orientation } \\
\text { strategy }\end{array}$ \\
\hline & & The innovation ability of master degree \\
\hline & & $\begin{array}{c}\text { Innovative undertaking supervision } \\
\text { mechanism }\end{array}$ \\
\hline & \multirow{2}{*}{ platform } & $\begin{array}{c}\text { Use of innovative entrepreneurial } \\
\text { hardware }\end{array}$ \\
\hline & & $\begin{array}{l}\text { Use soft environment for innovation } \\
\text { entrepreneurship }\end{array}$ \\
\hline
\end{tabular}

\section{Construction of a Combination Evaluation System Based on Reliability Analysis}

Reliability Analysis of Evaluation Results.There are $n$ evaluation objects and $m$ comprehensive evaluation model. $X_{\mathrm{ij}}$ indicated that the evaluation model of the $\mathrm{i}$ was evaluated by the $\mathrm{j}$ comprehensive evaluation model. $T_{i}$ represents the real value of the ith evaluation object, and $E_{i j}$ represents the error, I $=1,2 \ldots, \mathrm{n} . \mathrm{J}=1,2, \ldots \mathrm{M}$, according to the reliability theory, the actual value of the evaluation $\mathrm{X}_{\mathrm{ij}}$ is the sum of the true value $\mathrm{T}_{\mathrm{i}}$ and the judgment error $\mathrm{E}_{\mathrm{ij}}$, there is:

$\mathrm{X}_{i j}=T_{i}+E_{i j}$

Here are two assumptions:

Assumption 1: Eij and Ti are independent of each other

Assumption 2: Eij and Eik are independent of each other

According to assumption 1, there is a single comprehensive evaluation model

$$
\sigma_{\mathrm{X}_{j}}^{2}=\sigma_{T}^{2}+\sigma_{E_{j}}^{2}
$$


Its reliability coefficient is defined as:

$$
r_{j}=\frac{\sigma_{T}^{2}}{\sigma_{X_{j}}^{2}}=1-\frac{\sigma_{E_{j}}^{2}}{\sigma_{X_{j}}^{2}}
$$

there are $n$ kinds of comprehensive evaluation models, and the new definition of reliability coefficient of the single evaluation model is:

$$
r=1-\frac{\sum \sigma_{E_{j}}^{2} / n}{\sum \sigma_{X_{j}}^{2} / n}=1-\frac{\sum \sigma_{E_{j}}^{2}}{\sum \sigma_{X_{j}}^{2}}
$$

The $\mathrm{r}$ here is the reliability, also known as the reliability coefficient.

$$
\begin{aligned}
& \text { As } \mathrm{X}_{i j}=T_{i}+E_{i j} \text { and } \mathrm{X}_{i k}=T_{i}+E_{i k} \text { and } \mathrm{X}_{i j}-\mathrm{X}_{i k}=E_{i j}-E_{i k} \\
& \sigma_{\mathrm{E}_{j}}^{2}+\sigma_{\mathrm{E}_{k}}^{2}=\sigma_{\mathrm{X}_{j}}^{2}+\sigma_{\mathrm{X}_{k}}^{2}-2 \sigma_{X_{j} X_{k}}
\end{aligned}
$$

$\operatorname{Sum} \mathrm{j}, \mathrm{j} \neq \mathrm{k}$,

$$
\sum_{\substack{j=1 \\ j \neq k}}^{n} \sigma_{E_{j}}^{2}+(n-1) \sigma_{E_{k}}^{2}=\sum_{\substack{j=1 \\ j \neq k}}^{n} \sigma_{X_{j}}^{2}+(n-1) \sigma_{X_{k}}^{2}-2 \sum_{\substack{j=1 \\ j \neq k}}^{n} \sigma_{X_{j} X_{k}}
$$

Sum $k, j \neq k$,

$$
(n-1) \sum_{\substack{j=1 \\ j \neq k}}^{n} \sigma_{E_{j}}^{2}+\sum_{\substack{j=1 \\ j \neq k}}^{n}(n-1) \sigma_{E_{j}}^{2}=\sum_{\substack{j=1 \\ j \neq k}}^{n} \sigma_{x_{j}}^{2}+\sum_{\substack{j=1 \\ j \neq k}}^{n}(n-1) \sigma_{E_{k}}^{2}-2 \sum_{\substack{j=1 \\ j \neq k}}^{n} \sum_{\substack{k=1 \\ k \neq j}}^{n} \sigma_{X_{j} X_{k}}
$$

There is:

$$
r=\frac{1}{(n-1)} \frac{\sum_{\substack{j=1 \\ j \neq k}}^{n} \sum_{\substack{k>1 \\ k \succ j}}\left(X_{j}-\overline{X_{i}}\right)\left(X_{k}-\overline{X_{i}}\right)}{\sum_{\substack{j=1 \\ j \neq k}}^{n} \sigma_{X_{i}}^{2}}
$$

By setting $\mathrm{j}$ as a constant and $\mathrm{k}$ as the variable, the reliability coefficient of the $\mathrm{j}$ comprehensive evaluation model can be derived as follows:

$$
r_{j}=\frac{\sum_{\substack{k=1 \\ k \succ j}}^{n}\left(X_{j}-\overline{X_{i}}\right)\left(X_{k}-\overline{X_{i}}\right)}{\sum_{\substack{k=1 \\ k \succ j}}^{n} \frac{1}{2}\left[\left(X_{j}-\overline{X_{i}}\right)^{2}+\left(X_{k}-\overline{X_{i}}\right)^{2}\right]}=\frac{\sum_{\substack{k=1 \\ k \succ j}}^{n} l_{j k}}{\sum_{\substack{k=1 \\ k \succ j}}^{n} \frac{\left(l_{j j}+l_{k k}\right)}{2}}
$$

The comprehensive reliability of the comprehensive evaluation model (R) is given by formula (10)

$$
R=\frac{m \bar{r}}{1+(m-1) \bar{r}}
$$

An Ex Post Facto Test of the Method of Evaluation. The pre-test of the combined evaluation system model is to verify that the sorting results of each single method of the composition model are consistent. The calculation formula of Kendall harmonious coefficient is usually used in advance inspection.

$$
C=\frac{\sum_{i=1}^{5} R_{i}^{2}-\frac{1}{n}\left(\sum_{i=1}^{n} R_{i}\right)^{2}}{\frac{1}{12} m^{2}\left(n^{3}-n\right)}
$$


$\mathrm{M}$ is the evaluation method, and $\mathrm{n}$ is the number of items of evaluation, which is the sum of the evaluation level of the evaluation of the I evaluation project in $\mathrm{M}$.

When the number of the number of assessed items $\mathrm{n}$ is greater than 7 , the inspection statistics are as follows:

$$
\chi^{2}=m(n-1) C
$$

$\chi^{2}$ is going to follow the n-1 $\chi^{2}$. distribution The $\chi_{n-1}^{2}(\alpha)$ confidence level found in the table. $\alpha$ was found at 0.05 or 0.01 . If $\chi^{2} \geq \chi_{n-1}^{2}(\alpha)$, then, the evaluation results of various evaluation methods are statistically significant $[9,10]$.

After the test of the combined evaluation system model, the main purpose is to verify the close degree of the result of the combined income sequence and the initial method. After the combined evaluation method, the spillman grade correlation coefficient test can be adopted. When $n$ is greater than 10 , the test statistic is:

$$
t_{k}=\rho_{k} \sqrt{\frac{n-2}{1-\rho_{k}^{2}}}
$$

$t_{k}$ represents the average correlation between the combination method $\mathrm{k}$ and the original $\mathrm{m}$ methods. $t_{k}$ rules by $\mathrm{n}-2 \mathrm{t}$ distribution.

\section{Conclusion}

The project put forward weighted combination evaluation model, the basic idea is to comprehensive evaluation model of the relative reliability of the results is introduced into the portfolio evaluation model, makes combination evaluation result more scientific and reasonable. Empirical analysis and post-test results show that the weighted combination evaluation model is more accurate than that of general assembly evaluation model.

\section{Acknowledgements}

The research conducted in this paper have been supported by the fund of Important Foundation of Jilin Provincial Education department.(2013395)

\section{References}

[1] Zhu Zhiting,Sun Yanyan:Theory of Educational Technology,Vol.1(2015).No.1,P14-21.

[2] Information on http://en.wikipedia.org/wiki/hackerspace/.

[3] Information on http://www.weareteachers.com/hot-topics6/special reports/.

[4] Guo Xianguang:Statistical Research,Vol.1(1995).No.5,P56-59.

[5] Zeng Xianbao:Statistical Research,Vol.1(1997).No.6,P56-58.

[6] Guo Yajun, Yi Pingtao:Chinese Journal of Management Science,Vol.14(2006).No.3,P60-64.

[7] He Xianglin: China Higher Education,Vol.1(2017).No.1,P51-53.

[8] Wen Lingyan,Zhu Li: Continue Education Research,Vol.1(2017).No.7,P56-59.

[9] Zhang Lijun,Chen Yu and Yuan Nengwen: Management Review,Vol.24(2012).No.05,P169-176.

[10] Huang Zhengnan: Chinese Journal of Health Statistics, Vol.17(2000).No.3,P154-156. 